\title{
Intraocular Pressure and Foveal Thickness After Phacoemulsification
}

\author{
YUAN-CHIEH LEE, FANG-LING CHUNG, AND CHIEN-CHUNG CHEN
}

- PURPOSE: To evaluate the natural course of intraocular pressure (IOP) and foveal thickness during the postoperative period, and the correlation between them.

- DESIGN: Prospective observational case series.

- METHODS: This institutional study comprised 30 eyes of 30 cataract patients scheduled for phacoemulsification. IOP and foveal thickness by optical coherence tomography (OCT) were measured preoperatively and three, six, nine, 12, 15, 18, 21, 24 hours, five days, one month, and two months postoperatively.

- RESUlTs: The IOP was $4.7 \pm 2.4 \mathrm{~mm} \mathrm{Hg}$ at three hours postoperatively. The IOP increased to $23.4 \pm 8.1$ $\mathrm{mm} \mathrm{Hg}$ at six hours and $23.5 \pm 7.3 \mathrm{~mm} \mathrm{Hg}$ at nine hours postoperatively. The IOP was $1.9 \mathrm{~mm} \mathrm{Hg}$ lower at one month or two months postoperatively than preoperatively. The foveal thickness was $202.1 \pm 19.2 \mu \mathrm{m}$ and significantly higher at three hours postoperatively, and was $182.3 \pm 20.5 \mu \mathrm{m}, 183.2 \pm 22.3 \mu \mathrm{m}$, and significantly lower at nine and 12 hours postoperatively than preoperatively. The correlation between mean IOP and mean foveal thickness is statistically significant. Fovea thickness (microns) $=207.0476-1.019759 \times$ IOP $(\mathrm{mm} \mathrm{Hg}), \mathrm{P}$ value $<.0001$, adjusted $\mathrm{R}^{2}=.8699$.

- CONCLUSIONS: We found initial hypotony, an IOP spike during six to nine hours, and a decrease of IOP at one month and two months postoperatively. An initial increase of the foveal thickness, a significant reduction at nine hours and 12 hours, and an equivocal increase at one month or two months postoperatively were also noted. A significant negative correlation between IOP and foveal thickness was shown. (Am J Ophthalmol 2007;144:203-208. (C) 2007 by Elsevier Inc. All rights reserved.)

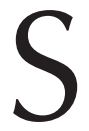

MALL-INCISION CATARACT SURGERY WITH IMPLANtation of a foldable intraocular lens (IOLs) is currently the preferred technique among cataract surgeons. A rise in intraocular pressure (IOP) and some

\section{Accepted for publication Apr 9, 2007.}

From the Department of Ophthalmology, Buddhist Tzu Chi General Hospital, Hualien, Taiwan (Y.C.L., F.L.C.), the Department of Ophthalmology, Buddhist Tzu Chi General Hospital, Taipei, Taiwan (Y.C.L.), the Department of Medicine, Tzu Chi University, Hualien, Taiwan (Y.C.L.), the Graduate Institute of Medical Sciences, Tzu Chi University, Hualien, Taiwan (Y.C.L.), and the Department of Ophthalmology, National Taiwan University Hospital, Taipei, Taiwan (Y.C.L., C.C.C.).

Inquiries to Yuan-Chieh Lee, Department of Ophthalmology, Buddhist Tzu Chi General Hospital, 707, Section 3, Chung Yang Road, Hualien 970, Taiwan; e-mail: derrick@url.com.tw degree of macular edema continue to occur after uneventful cataract surgery. An increase in IOP is the most frequent complication in the early postoperative period after cataract surgery, ${ }^{1}$ and the incidence of angiographic cystoid macular edema was $19 \%$ after uneventful phacoemulsification. ${ }^{2}$

Although an increase in IOP after small-incision cataract surgery has been widely reported, ${ }^{3-16}$ IOP was measured only once or twice in the early postoperative period in most studies. Only a few studies evaluated the natural course of IOP after small-incision cataract surgery. ${ }^{14,16}$

The introduction of optical coherence tomography (OCT) has enabled clinicians to measure macular thickness quantitatively. The latest OCT model (StratusOCT [OCT3]; Carl Zeiss Meditec, Dublin, California, USA) was made commercially available in 2002 . It provides a theoretical axial resolution $\leqq 10 \mu \mathrm{m}$, although this has not yet been proven in practice. ${ }^{17}$ OCT had been used to evaluate macular thickness changes after uneventful cataract surgery, ${ }^{18-25}$ but most studies evaluated macular thickness in the late postoperative period. Several recent reports showed that OCT may be useful in detecting hypotony maculopathy, ${ }^{26-29}$ while there was no report investigating the macular thickness changes as correlated with IOP.

The purpose of this study was to evaluate the natural course of IOP and foveal thickness during the postoperative period and the correlation between them.

\section{METHODS}

THIS PROSPECTIVE STUDY COMPRISED 30 EYES OF 30 CONsecutive cataract patients scheduled for small clear corneal incision cataract surgery and implantation of a foldable IOL. Exclusion criteria were diabetes mellitus, previous ocular surgery, glaucoma or ocular hypertension, or any retinal disorder. Patients were excluded if the IOP recorded before inclusion ever exceeded $21 \mathrm{~mm} \mathrm{Hg}$; if they were taking corticosteroids, which could increase IOP; or if they had a corneal abnormality that prevented a reliable IOP measurement. Patients were also excluded if any macular lesion was detected by OCT; or if cataract was so dense that an OCT examination was impossible or unreliable.

All patients were operated by the same surgeon (Y.C.L.). Tropicamide $0.5 \%$ was given for mydriasis 30 minutes before surgery. Topical alcaine anesthesia, tempo- 
ral clear corneal incision, soft-shell technique ${ }^{30}$ with Duovisc (Alcon Laboratories, Inc, Fort Worth, Texas, USA), divide-and-conquer phacoemulsification, implantation of a single-piece foldable IOLs (Acrysof Single-Piece IOL; Alcon Laboratories, Inc, Fort Worth, Texas, USA), rock'n roll technique ${ }^{31}$ to remove the ophthalmic viscosurgical devices (OVD) as possible, closure of the clear cornea wound with one stitch 10-0 nylon suture, and wound sealing confirmed by intraoperative Seidel testing were applied to all the patients.

Betamethasone ophthalmic solution $0.1 \%$ and gentamycin ophthalmic solution $0.3 \%$ were applied every three hours on the first postoperative day, four times a day in the following four days. Then the medication was changed on day six into betamethasone ophthalmic solution $0.1 \%$ and sulfamethoxazole ophthalmic solution $4 \%$ four times a day until two months postoperatively.

IOP was measured by a noncontact pneumotonometer (NT 2000, Nidek Co, Ltd, Gamagori, Japan), and foveal thickness was measured and analyzed by StratusOCT3 with software version 4.0. On capturing images of OCT, standard procedures were followed to obtain optimal quality scans for analysis. The subjects were asked to look into the objective lens and determine if the point of intersection of the red scan lines was coincident with the center of the green fixation target. If so, the subjects were asked to fix on the green fixation target and no further fixation adjustment was needed. Those who could not see the green fixation target or red scan lines were excluded. The Fast Macular Thickness Acquisition scan was used to acquire six $6.0 \mathrm{~mm}$ scans over 1.92 seconds of scanning. Care was taken to select scans that identified the retina's inner limiting membrane (ILM) and the retinal pigment epithelium (RPE). Only analysis prints that displayed an accurately identified ILM and RPE boundary were acceptable. Retinal thickness was measured as the distance between these two interfaces at each measurement point along the $\mathrm{x}$-axis of the scan. Foveal thickness was defined as the average retinal thickness of a central disk area, $1.0 \mathrm{~mm}$ in diameter, centered on the fixation of the patient. The measurements of IOP and foveal thickness were performed by the same experienced operator at just before operation, every three hours on the first postoperative day (that is three, six, nine, $12,15,18,21$, and 24 hours postoperatively), five days, one month, and two months postoperatively. Three readings were taken for both IOP and OCT, and the average of the three readings was used each time. We certified that all applicable institutional and governmental regulations concerning the ethical use of human volunteers were followed during this research.

- StAtistical ANAlysis: Paired $t$ test was used to compare the differences between preoperative and postoperative IOP and foveal thickness measurements. A $P$ value of .05 or less was considered statistically significant. However, because of the large number of comparisons ( 11 for
TABLE 1. The Intraocular Pressure Measurements Before and After Phacoemulsification $(n=30)$

\begin{tabular}{lrc}
\hline \multicolumn{1}{c}{ Time } & IOP $(\mathrm{mm} \mathrm{Hg})$ & $P$ value \\
\hline Postoperative (baseline) & $14.5 \pm 2.9$ & \\
\hline Postoperative 3 hours & $4.7 \pm 2.4$ & $<.0001^{\neq}$ \\
\hline Postoperative 6 hours & $23.4 \pm 8.1$ & $<.0001^{\neq}$ \\
\hline Postoperative 9 hours & $23.5 \pm 7.3$ & $<.0001^{\neq}$ \\
Postoperative 12 hours & $22.0 \pm 6.2$ & $<.0001^{\neq}$ \\
\hline Postoperative 15 hours & $19.4 \pm 5.0$ & $<.0001^{\neq}$ \\
\hline Postoperative 18 hours & $18.8 \pm 4.9$ & $<.0001^{\neq}$ \\
\hline Postoperative 21 hours & $17.2 \pm 4.2$ & $.0003^{\neq}$ \\
Postoperative 24 hours & $16.9 \pm 4.7$ & .0086 \\
\hline Postoperative 5 days & $13.2 \pm 3.4$ & .0122 \\
\hline Postoperative 1 month & $12.6 \pm 3.0$ & $.0001^{\neq}$ \\
\hline Postoperative 2 months & $12.6 \pm 2.7$ & $<.0001^{\neq}$ \\
\hline
\end{tabular}

IOP = intraocular pressure.

${ }^{*}$ Comparison was significantly different from baseline at the .05 level by paired $t$ test and the Bonferroni adjustment.

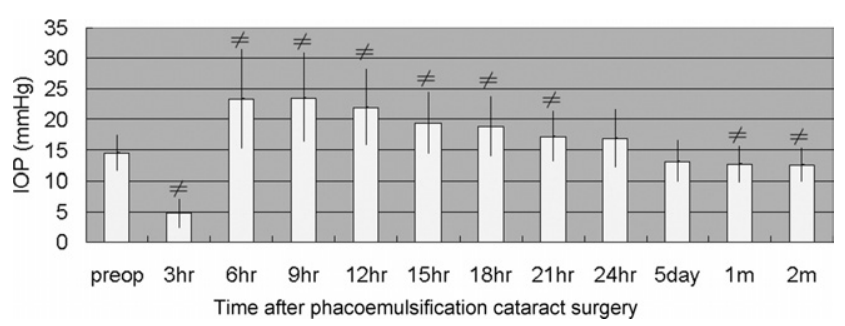

FIGURE 1. Bar graph showing intraocular pressure (IOP) before and after phacoemulsification. $\left({ }^{\neq}\right)$Comparison with preoperative IOP was significantly different at the .05 level by paired $t$ test and the Bonferroni adjustment.

both IOP and foveal thickness measurements), the Bonferroni adjustment was used to lower the chance of a statistically significant difference based on chance alone. The significance level was divided by the number of comparisons (11) using the Bonferroni adjustment. Thus, the $P$ value must be less than .0045 to be considered statistically significant. Simple linear regression was used to detect the correlation between IOP and foveal thickness. The Student $t$ test was used to compare the foveal thickness between those who had IOP equal to or less than $5 \mathrm{~mm} \mathrm{Hg}$ and those whose IOP measurements were higher than $5 \mathrm{~mm} \mathrm{Hg}$ at three hours postoperatively. The software Stata 8.0 (StataCorp LP, College Station, Texas, USA) was used for statistical analysis.

\section{RESULTS}

THE MEAN AGE OF 21 MEN AND NINE WOMEN WAS $68.4 \pm 9.4$ years (range, 53 to 85 years). Table 1 and Figure 1 shows the course of IOP over time. Compared with preopera- 


\begin{tabular}{|ll}
\hline \multicolumn{3}{c}{ TABLE 2. The Foveal Thickness Before and After } \\
Phacoemulsification $(\mathrm{n}=30)$
\end{tabular}

OCT $=$ optical coherence tomography.

${ }^{\neq}$Comparison was significantly different from baseline at the .05 level by paired $t$ test and the Bonferroni adjustment.

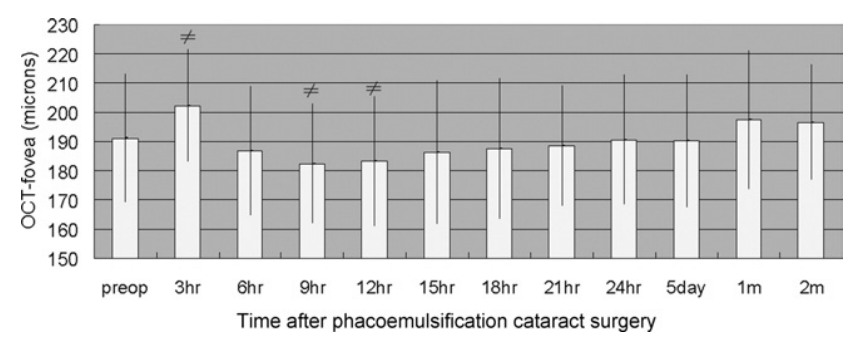

FIGURE 2. Bar graph showing foveal thickness before and after phacoemulsification. $\left({ }^{\neq}\right)$Comparison with preoperative intraocular pressure (IOP) was significantly different at the .05 level by paired $t$ test and the Bonferroni adjustment.

tively, the IOP was significantly lower at three hours, one month, or two months postoperatively and significantly higher at six, nine, $12,15,18$, or 21 hours postoperatively.

Table 2 and Figure 2 shows the course of foveal thickness. The foveal thickness was significantly higher at three hours postoperatively, and was significantly lower at nine and 12 hours postoperatively than preoperatively.

Figure 3 shows the relationship between IOP and foveal thickness. Fovea thickness (microns) $=207.0476$ $-1.019759 \times \mathrm{IOP}(\mathrm{mm} \mathrm{Hg})$, the $P$ value $<.0001$, and the adjusted $\mathrm{R}^{2}=.8699$. The correlation between IOP and foveal thickness is statistically significant.

There were 22 patients with IOP measurements equal to or less than $5 \mathrm{~mm} \mathrm{Hg}$ and eight patients with IOP higher than $5 \mathrm{~mm} \mathrm{Hg}$ at three hours postoperatively. In those patients who had IOP measurements equal to or less than $5 \mathrm{~mm} \mathrm{Hg}$, the foveal thickness was $202.7 \pm 19.0 \mu \mathrm{m}$. In those patients with IOP higher than $5 \mathrm{~mm} \mathrm{Hg}$, the foveal thickness was $200.6 \pm 20.9 \mu \mathrm{m}$. There was no significant difference between these two groups.

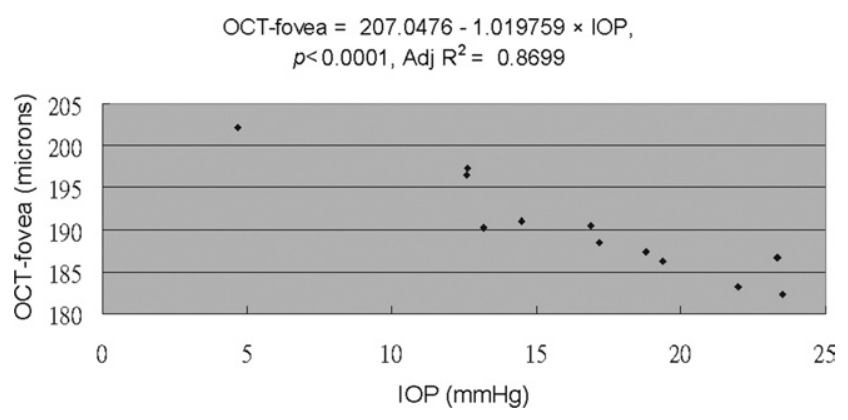

FIGURE 3. The correlation between intraocular pressure (IOP) and foveal thickness before and after phacoemulsification. Each $\downarrow$ represented the mean IOP and mean foveal thickness at a given time. A significant negative correlation between mean IOP and mean foveal thickness was found.

\section{DISCUSSION}

WE FOUND INITIAL HYPOTONY WITHIN THE THREE HOURS after surgery. Our finding was similar to that of Shingleton and associates ${ }^{32}$ who found initial hypotony $(<5 \mathrm{~mm} \mathrm{Hg})$ in $20.5 \%$ of eyes 30 minutes postoperatively, and of Vasavada and associates ${ }^{14}$ who found initial hypotony within two hours after surgery. The hypotony in our study was transient and IOP was elevated to $23.4 \pm 8.1 \mathrm{~mm} \mathrm{Hg}$ six hours postoperatively. A recent study by Masket and Belani suggested that IOP remained reasonably stable relative to the level set at the conclusion of the procedure in the presence of a sealed clear corneal wound. ${ }^{33}$ In their study, IOP was measured intraoperatively at the conclusion of each procedure and set between $15 \mathrm{~mm} \mathrm{Hg}$ and 20 $\mathrm{mm} \mathrm{Hg}$. No patient had an IOP less than $10 \mathrm{~mm} \mathrm{Hg}$ between two hours and six hours after the conclusion of each procedure. They suggested proper wound construction to prevent short-term ocular hypotony after corneal incision cataract surgery. In our study, wound sealing was also confirmed at the conclusion of each procedure, but initial hypotony was noted in most cases. We believe that the key is the IOP setting at the conclusion of procedure. Our surgeon set the IOP low at the conclusion of the procedure for prevention of high IOP spike postoperatively. The IOP might remain stable during the early hours postoperatively, just as Masket and Belani suggested. There was reasonably initial hypotony in our study.

The course of IOP increase after cataract surgery was different between previous two studies. In the study of Rainer and associates, peribulbar anesthesia and chondroitin sulfate 4\%-sodium hyaluronate 3\% (Viscoat; Alcon Laboratories, Inc, Fort Worth, Texas, USA) as OVD were used, and the IOP was measured by Schiøtz tonometry and adjusted to $20 \mathrm{~mm} \mathrm{Hg}$ at the end of surgery. The mean IOP reached the peak increase of $13.4 \pm 9.4 \mathrm{~mm} \mathrm{Hg}$ after one hour. ${ }^{16}$ In the study of Vasavada and associates, hydroxypropyl methylcellulose 2\% (Viscomet; Milmet 
Laboratories Pvt, Ltd, Baroda, India) was used as OVD, and the IOP peaked between six hours and 10 hours postoperatively. ${ }^{14}$ Our data showed that the IOP spike occurred between six hours to nine hours postoperatively, similar to the study of Vasavada and associates.

The IOP was significantly lower at one month (12.6 \pm $3.0 \mathrm{~mm} \mathrm{Hg})$ and two months $(12.6 \pm 2.7 \mathrm{~mm} \mathrm{Hg})$ postoperatively than preoperatively $(14.5 \pm 2.9 \mathrm{~mm} \mathrm{Hg})$. A similar finding was noted in the study of Schwenn and associates. ${ }^{9}$ Although statistical significance was not identified, they reported a decrease of $0.6 \mathrm{~mm} \mathrm{Hg}$ in the sclerocorneal tunnel group and a decrease of $1.5 \mathrm{~mm} \mathrm{Hg}$ in the clear corneal group at five months postoperatively. In our study with temporal clear corneal incision, the mean $\mathrm{IOP}$ at two months postoperatively was $1.9 \mathrm{~mm} \mathrm{Hg}$ lower than the mean IOP preoperatively.

Since the introduction of OCT, the study of changes of macular thickness after cataract surgery has drawn much interest. However, a conclusive result has not been reached yet. Some studies found no statistical difference. ${ }^{19,20}$ Some studies reported that macular thickness increased after cataract surgery. ${ }^{18,21,24}$ Others reported a decrease of foveal thickness after cataract surgery, ${ }^{22,23}$ though measurement with retina thickness analyzer (RTA) as the key instrument was criticized in Cohen and Patel's study. ${ }^{34}$ In spite of the diversity of results, a consensus is that the changes, if they exist, occur primarily in the central macular region. ${ }^{21,23,24}$ Therefore, foveal thickness was used as the main parameter in our study.

The foveal thickness measurement was $191.0 \pm 22.0$ $\mu \mathrm{m}$ preoperatively, increased to $202.1 \pm 19.2 \mu \mathrm{m}$ at three hours postoperatively, and then decreased to $182.3 \pm 20.5$ $\mu \mathrm{m}$ at nine hours and $183.2 \pm 22.3 \mu \mathrm{m}$ at 12 hours postoperatively. After that, it increased and measured $196.6 \pm 19.8 \mu \mathrm{m}$ at two months postoperatively. The $P$ value of the comparison from preoperative baseline was .0372 for postoperative one month and .0345 for postoperative two months. They did not reach statistical significance because we used a strict statistical method the Bonferroni adjustment. Statistical use of the Bonferroni adjustment is sometimes questionable. It is highly conservative and reduces the type I error, but it may falsely increase the type II error and may miss real differences.

Previous reports showed that OCT may be useful in detecting hypotony maculopathy after filtering surgery, ${ }^{26-29}$ and an increase of retinal thickness in the fovea with hypotony was noted. ${ }^{26,28}$ In our study, the foveal thickness was increased from $191.0 \pm 22.0 \mu \mathrm{m}$ preoperatively to $202.1 \pm 19.2 \mu \mathrm{m}$ three hours postoperatively, when hypotony was also noted. The foveal thickness was significantly reduced at nine hours and 12 hours postoperatively, when elevation of IOP was also noted. Thus, the dynamic changes of the mean foveal thickness seemed to run an inverse course to mean IOP. A significant negative correlation between mean IOP and mean foveal thickness was found in our study.

The difference of foveal thickness was not statistically significant between those who had IOP measurements equal to or less than $5 \mathrm{~mm} \mathrm{Hg}$ and those whose IOP measurements were higher than $5 \mathrm{~mm} \mathrm{Hg}$ at three hours postoperatively. Although we separated them into those who did and did not have hypotony soon after surgery, there was not much difference of IOP between these two groups. In fact, seven out of eight patients whose IOP measurements were higher than $5 \mathrm{~mm} \mathrm{Hg}$ had IOP less than $10 \mathrm{~mm} \mathrm{Hg}$. Besides, the case number was 22 and eight in each group, which led to insufficient power to detect the difference. The standard deviation of macular thickness was about $20 \mu \mathrm{m}$ in our study and also in another study. ${ }^{36}$ It takes a large sample size to detect true small difference with that standard deviation.

The correlation between IOP and foveal thickness was an interesting finding in our study, though the cause effect relationship could not be established. We did not think that IOP alone was causing the changes of foveal thickness. But for inflammatory mediators, profound hypotony with vessel leakage of just opening the eye, recurrent high and low IOP of phacoemulsification, etc, IOP might not be able to cause the changes. As we all know, there are blood-retina barrier and blood-aqueous barrier. We believe that only when these barriers are affected can IOP cause such changes of foveal thickness. Hypotony maculopathy, which showed increased foveal thickness by OCT, resolved after elevation of IOP. ${ }^{26-28}$ Kokame and associates $^{27}$ suggested application of a modified concept of the hypothesis by Starling ${ }^{35}-\mathrm{F}=\mathrm{C} \times[(\mathrm{Phc}-\mathrm{Pht})+($ Pcollt Pcollc)], where $\mathrm{C}=$ constant, $P$ hc $=$ mean hydrostatic pressure in capillary, $\mathrm{Pht}=$ hydrostatic pressure in tissue fluid, Pcollt $=$ colloid osmotic pressure in tissue fluid, and Pcollc $=$ mean colloid osmotic pressure in capillary. Low IOP represents low tissue hydrostatic pressure, resulting in a higher hydrostatic pressure gradient across retinal capillaries, which promotes a net movement of fluid into the extracellular spaces. Higher IOP means higher hydrostatic tissue pressure in the Starling law and results in less outflow of fluid from retinal capillaries. This might also be applicable to macular edema after cataract surgery. If increased foveal thickness measured by OCT means macular edema, elevated IOP might have a favorable effect on macular edema after phacoemulsification. This does not mean that we should leave high IOP alone, which of course leads to axon damage. But postoperative, mild, and short-term elevation of IOP, which is tolerable to optic nerve, might deserve observation instead of aggressive treatment to lower IOP. Further study is needed to confirm this theory.

In summary, we found initial hypotony, an IOP spike during six to nine hours, and a decrease of IOP at one 
month and two months postoperatively. An initial increase of the foveal thickness, a significant reduction at nine hours and 12 hours, and an equivocal increase at one month or two months postoperatively were also noted. A significant negative correlation between IOP and foveal thickness was shown.

THE AUTHORS INDICATE NO FINANCIAL SUPPORT OR FINANCIAL CONFLICT OF INTEREST. INVOLVED IN DESIGN OF STUDY (Y.C.L.); conduct of study (Y.C.L.); collection (Y.C.L., F.L.C.); management (Y.C.L.); analysis and interpretation of the data (Y.C.L., C.C.C.); preparation (Y.C.L.); review (Y.C.L., C.C.C.); and approval of the manuscript (Y.C.L., F.L.C., C.C.C.). Written informed consent according to the tenets of the Declaration of Helsinki was obtained from each patient included.

\section{REFERENCES}

1. Ahmed II, Kranemann C, Chipman M, Malam F. Revisiting early postoperative follow-up after phacoemulsification. J Cataract Refract Surg 2002;28:100-108.

2. Ursell PG, Spalton DJ, WHitcup SM, Nussenblatt RB. Cystoid macular edema after phacoemulsification: relationship to blood-aqueous barrier damage and visual acuity. J Cataract Refract Surg 1999;25:1492-1497.

3. Fry LL. Postoperative intraocular pressure rises: a comparison of Healon, Amvisc, and Viscoat. J Cataract Refract Surg 1989;15:415-420.

4. Kohnen T, von Ehr M, Schutte E, Koch DD. Evaluation of intraocular pressure with Healon and Healon GV in sutureless cataract surgery with foldable lens implantation. J Cataract Refract Surg 1996;22:227-237.

5. Rainer G, Menapace R, Findl O, Georgopoulos M, Kiss B, Petternel V. Intraocular pressure after small incision cataract surgery with Healon5 and Viscoat. J Cataract Refract Surg 2000;26:271-276.

6. Schwenn O, Dick HB, Krummenauer F, Christmann S, Vogel A, Pfeiffer N. Healon5 versus Viscoat during cataract surgery: intraocular pressure, laser flare and corneal changes. Graefes Arch Clin Exp Ophthalmol 2000;238:861-867.

7. Rainer G, Menapace R, Findl O, et al. Intraocular pressure rise after small incision cataract surgery: a randomized intraindividual comparison of two dispersive viscoelastic agents. Br J Ophthalmol 2001;85:139-142.

8. Holzer MP, Tetz MR, Auffarth GU, Welt R, Volcker HE. Effect of Healon 5 and 4 other viscoelastic substances on intraocular pressure and endothelium after cataract surgery. J Cataract Refract Surg 2001;27:213-218.

9. Schwenn O, Dick HB, Krummenauer F, Krist R, Pfeiffer N. Intraocular pressure after small incision cataract surgery: temporal sclerocorneal versus clear corneal incision. J Cataract Refract Surg 2001;27:421-425.

10. Rainer G, Menapace R, Findl O, Petternel V, Kiss B, Georgopoulos M. Intraindividual comparison of the effects of a fixed dorzolamide-timolol combination and latanoprost on intraocular pressure after small incision cataract surgery. J Cataract Refract Surg 2001;27:706-710.

11. Thirumalai B, Baranyovits PR. Intraocular pressure changes and the implications on patient review after phacoemulsification. J Cataract Refract Surg 2003;29:504-507.

12. Tranos PG, Wickremasinghe SS, Hildebrand D, et al. Sameday versus first-day review of intraocular pressure after uneventful phacoemulsification. J Cataract Refract Surg 2003;29:508-512.

13. Rainer G, Menapace R, Findl O, et al. Effect of a fixed dorzolamide-timolol combination on intraocular pressure after small-incision cataract surgery with Viscoat. J Cataract Refract Surg 2003;29:1748-1752.

14. Vasavada AR, Mamidipudi PR, Minj M. Relationship of immediate intraocular pressure rise to phaco-tip ergonomics and energy dissipation. J Cataract Refract Surg 2004;30:137-143.

15. Yachimori R, Matsuura T, Hayashi K, Hayashi H. Increased intraocular pressure and corneal endothelial cell loss following phacoemulsification surgery. Ophthalmic Surg Lasers Imaging 2004;35:453-459.

16. Rainer G, Menapace R, Schmid KE, et al. Natural course of intraocular pressure after cataract surgery with sodium chondroitin sulfate 4\%-sodium hyaluronate 3\% (Viscoat). Ophthalmology. 2005;112:1714-1718.

17. Jaffe GJ, Caprioli J. Optical coherence tomography to detect and manage retinal disease and glaucoma. Am J Ophthalmol 2004;137:156-169.

18. Sourdille P, Santiago PY. Optical coherence tomography of macular thickness after cataract surgery. J Cataract Refract Surg 1999;25:256-261.

19. Grewing R, Becker H. Retinal thickness immediately after cataract surgery measured by optical coherence tomography. Ophthalmic Surg Lasers 2000;31:215-217.

20. Cheng B, Liu Y, Liu X, Ge J, Ling Y, Zheng X. Macular image changes of optical coherence tomography after phacoemulsification. Zhonghua Yan Ke Za Zhi 2002;38:265-267.

21. Lobo CL, Faria PM, Soares MA, Bernardes RC, Cunha-Vaz JG. Macular alterations after small-incision cataract surgery. J Cataract Refract Surg 2004;30:752-760.

22. Cohen KL, Patel SB, Ray N. Retinal thickness measurement after phacoemulsification. J Cataract Refract Surg 2004;30: 1501-1506.

23. Ching HY, Wong AC, Wong CC, Woo DC, Chan CW. Cystoid macular oedema and changes in retinal thickness after phacoemulsification with optical coherence tomography. Eye 2006;20:297-303.

24. Nicholas S, Riley A, Patel H, Neveldson B, Purdie G, Wells AP. Correlations between optical coherence tomography measurement of macular thickness and visual acuity after cataract extraction. Clin Experiment Ophthalmol 2006;34:124-129.

25. Biro Z, Balla Z, Kovacs B. Change of foveal and perifoveal thickness measured by OCT after phacoemulsification and IOL implantation. Eye. Forthcoming.

26. Klink T, Lieb WE, Gobel W. Early and late findings with optical coherence tomography (OCT) in patients with postoperative hypotonia. Ophthalmologe 2000;97:353-358.

27. Kokame GT, de Leon MDL, Tanji T. Serous retinal detachment and cystoid macular edema in hypotony maculopathy. Am J Ophthalmol 2001;131:384-386.

28. Karasheva G, Goebel W, Klink T, Haigis W, Franz G. Changes in macular thickness and depth of anterior chamber 
in patients after filtration surgery. Graefe's Arch Clin Exp Ophthalmol 2003;241:170-175.

29. Budenz DL, Schwartz K, Gedde SJ. Occult hypotony maculopathy diagnosed with optical coherence tomography. Arch Ophthalmol 2005;123:113-114.

30. Arshinoff SA. Dispersive-cohesive viscoelastic soft shell technique. J Cataract Refract Surg 1999;25:167-173.

31. Zetterstrom C, Wejde G, Taube M. Healon5: comparision of 2 removal techniques. J Cataract Refract Surg 2002;28:1561-1564.

32. Shingleton BJ, Wadhwani RA, O'Donoghue MW, Baylus S, Hoey H. Evaluation of intraocular pressure in the immediate period after phacoemulsification. J Cataract Refract Surg 2001;27:524-527.
33. Masket S, Belani S. Proper wound construction to prevent short-term ocular hypotony after clear corneal incision cataract surgery. J Cataract Refract Surg 2007;33:383-386.

34. Liu DT, Lee VY, Lam DS, Chan WM. Retinal thickness measurement after phacoemulsification. J Cataract Refract Surg 2005;31:1269-1270; author reply 1270 .

35. Alm A, Bill A. Ocular circulation. In: Hart WM, editor. Adler's physiology of the eye: clinical application. 9th ed. St Louis, Missouri: Mosby, 1992:220-221.

36. Chan A, Duker JS, Ko TH, Fujimoto JG, Schuman JS. Normal macular thickness measurements in healthy eyes using Stratus optical coherence tomography. Arch Ophthalmol 2006;124:193-198.

\section{REPORTING VISUAL ACUITIES}

The AJO encourages authors to report the visual acuity in the manuscript using the same nomenclature that was used in gathering the data provided they were recorded in one of the methods listed here. This table of equivalent visual acuities is provided to the readers as an aid to interpret visual acuity findings in familiar units.

Table of Equivalent Visual Acuity Measurements

\begin{tabular}{|c|c|c|c|c|}
\hline \multicolumn{3}{|c|}{ Snellen Visual Acuities } & \multirow[b]{2}{*}{ Decimal Fraction } & \multirow[b]{2}{*}{ LogMAR } \\
\hline 4 Meters & 6 Meters & 20 Feet & & \\
\hline $4 / 40$ & $6 / 60$ & $20 / 200$ & 0.10 & +1.0 \\
\hline $4 / 32$ & $6 / 48$ & $20 / 160$ & 0.125 & +0.9 \\
\hline $4 / 25$ & $6 / 38$ & $20 / 125$ & 0.16 & +0.8 \\
\hline $4 / 20$ & $6 / 30$ & $20 / 100$ & 0.20 & +0.7 \\
\hline $4 / 16$ & $6 / 24$ & $20 / 80$ & 0.25 & +0.6 \\
\hline $4 / 12.6$ & $6 / 20$ & $20 / 63$ & 0.32 & +0.5 \\
\hline $4 / 10$ & $6 / 15$ & $20 / 50$ & 0.40 & +0.4 \\
\hline $4 / 8$ & $6 / 12$ & $20 / 40$ & 0.50 & +0.3 \\
\hline $4 / 6.3$ & $6 / 10$ & $20 / 32$ & 0.63 & +0.2 \\
\hline $4 / 5$ & $6 / 7.5$ & $20 / 25$ & 0.80 & +0.1 \\
\hline $4 / 4$ & $6 / 6$ & $20 / 20$ & 1.00 & 0.0 \\
\hline $4 / 3.2$ & $6 / 5$ & $20 / 16$ & 1.25 & -0.1 \\
\hline $4 / 2.5$ & $6 / 3.75$ & $20 / 12.5$ & 1.60 & -0.2 \\
\hline $4 / 2$ & $6 / 3$ & $20 / 10$ & 2.00 & -0.3 \\
\hline
\end{tabular}

From Ferris FL III, Kassoff A, Bresnick GH, Bailey I. New visual acuity charts for clinical research. Am J Ophthalmol 1982;94:91-96. 


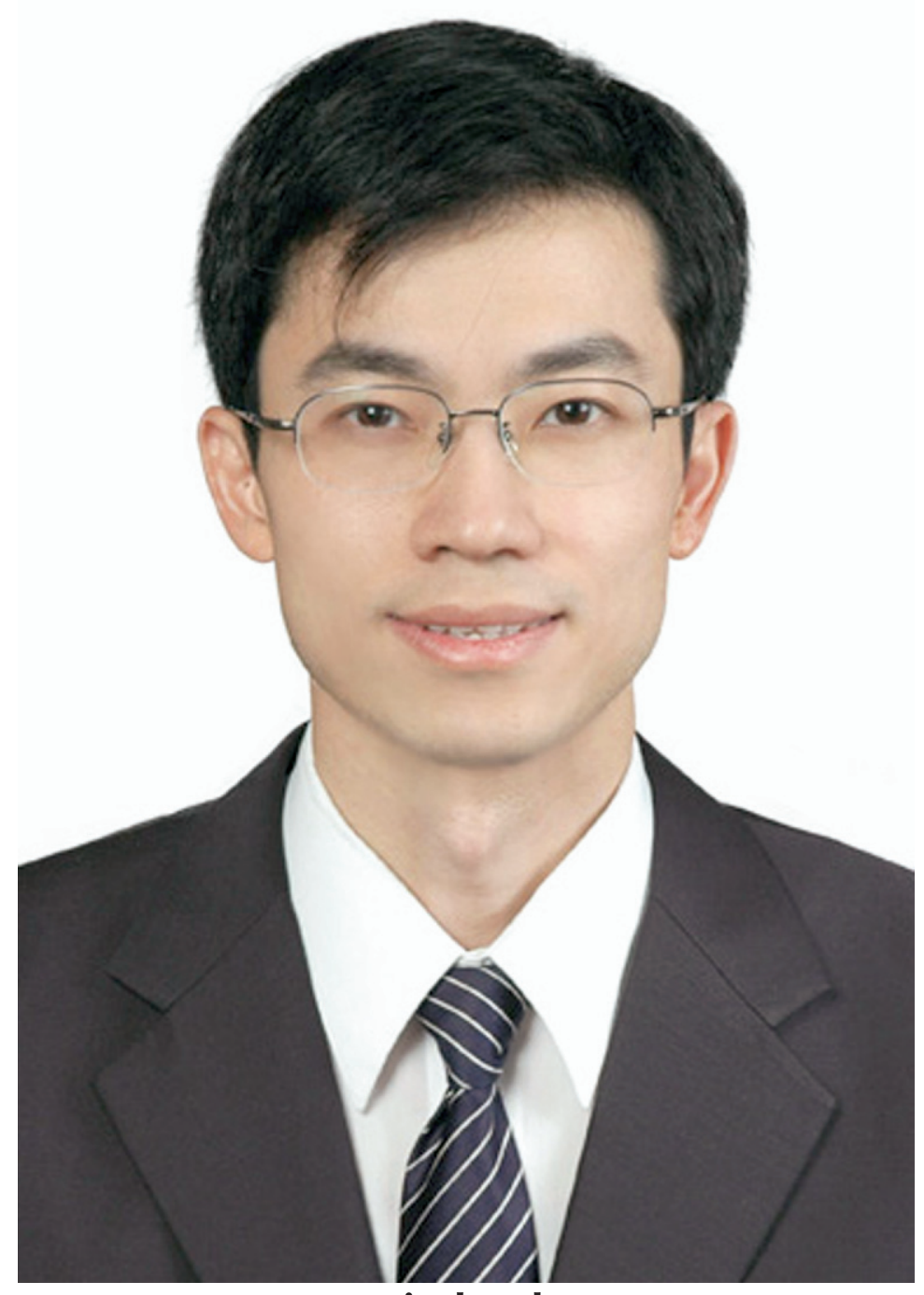

Biosketch

Yuan-Chieh Lee, MD, received his medical degree from National Taiwan University, Taipei, Taiwan and completed a residency and a fellowship at the National Taiwan University Hospital. He was chair of Department of Ophthalmology, Buddhist Tzu Chi General Hospital, Hualien, Taiwan, in 2002. He received award from the Ophthalmolgic Society of Taiwan in 2004. Dr Lee is a subspecialist in refractive surgery, cornea and external diseases. But his research interests also include retinal circulation and ocular pharmacology. 


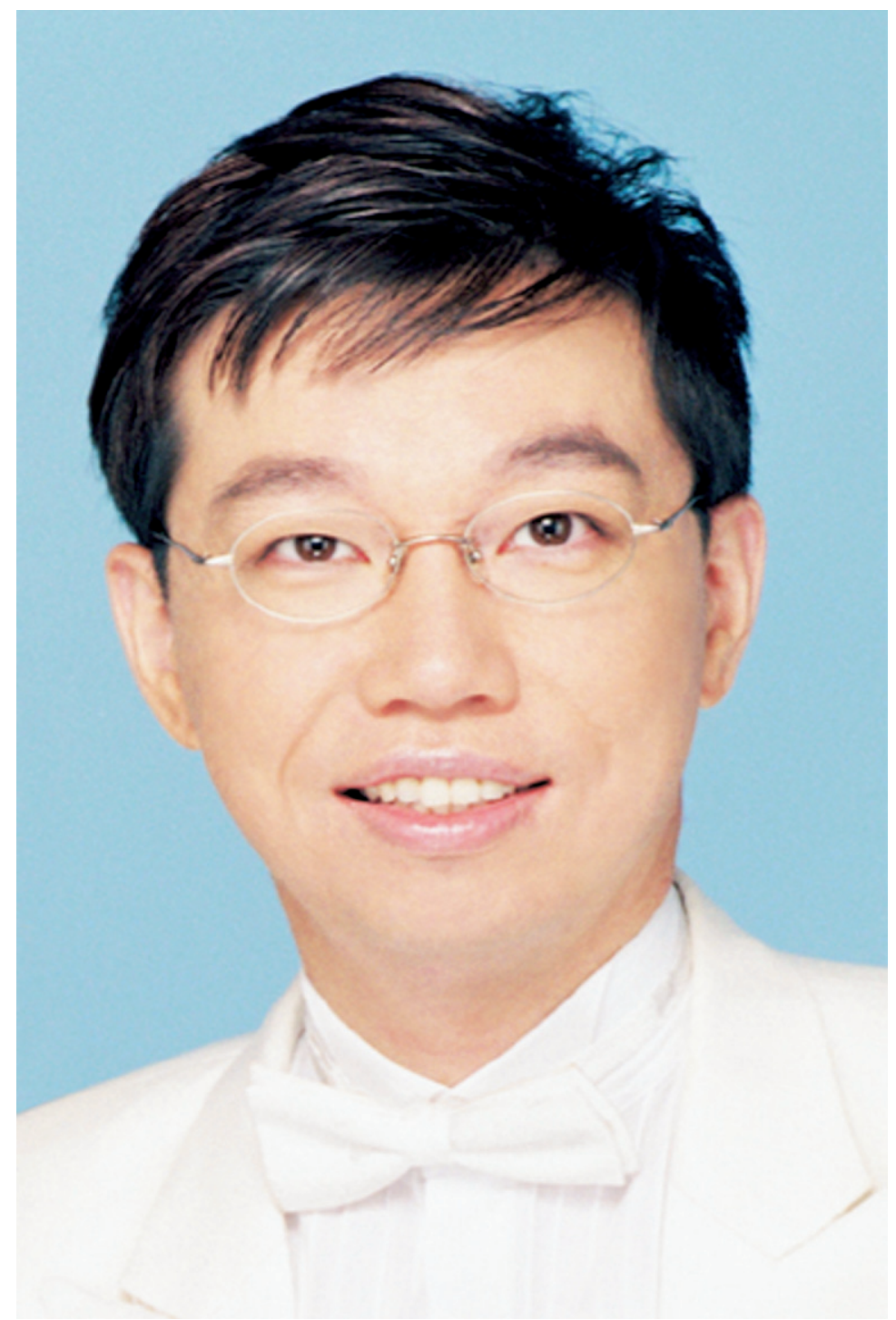

\section{Biosketch}

Chien-Chung Chen, MD, was born and raised in Taiwan where he received his medical degree from National Taiwan University (NTU), Taipei, Taiwan, in 1998 and completed a residency and fellowship in both corneal and retinal diseases in NTU Hospital in 2003. Dr Chen attended Buddhist Tzu Chi General Hospital and En Chu Kong Hospital in turn by 2005, and is currently the ophthalmologist of the Department of Ophthalmology at NTU Hospital and Sun Rise Eye Clinic. 